\title{
Study of the soot quantification for two-stage injection of diesel in a constant-volume combustion chamber
}

\author{
Jiawei Cao ${ }^{1}$, Zhixia He ${ }^{* 2}$, Bei $\mathrm{Li}^{1}$, Wenjun Zhong ${ }^{1}$, Mei Wang ${ }^{1}$ \\ ${ }^{1}$ School of Energy Power Engineering, Jiangsu University, Zhenjiang, China \\ ${ }^{2}$ Institute of Energy Research, Jiangsu University, Zhenjiang, China \\ *Corresponding author: zxhe@ujs.edu.cn
}

\begin{abstract}
The effect of two-stage injection strategies on the soot formation of $0 \#$ fossil diesel were investigated experimentally using a constant volume combustion chamber. The ambient conditions was kept constant as injection pressure 150 $\mathrm{MPa}$, ambient gas temperature $900 \mathrm{~K}$, ambient gas pressure 45 bar. A high-speed diffused back-illumination extinction imaging technique was employed to make quantitative measurement on temporal soot evolution and reacting spray liquid length and a direct high-speed camera was used to measure the ignition delay. Two-stage injection strategies were varied with different pilot and main injection time, including a sweep of dwell time in pilotmain injection and pilot injection duration. The results show that the ignition delay decreases with the increasing dwell time. It may result from the entrained surrounding gas enhance the spray combustion process. In the reacting condition, the liquid-phase penetration is slightly longer with the shorter dwell time. However, the pilot injection duration shows slighter impact. The longer dwell time contributes to more total soot mass while the different pilot injection duration barely affect the total soot mass of the main injection.
\end{abstract}

\section{Keywords}

Diesel; two-stage injection; Soot; Combustion chamber

\section{INTRODUCTION}

Diesel engines have been employed extensively due to its outstanding efficiency and power output. However, enormous soot emission from the conventional diesel cannot meet the strict emission regulation. Multiple injection technology has been a practical method to reduce the carbon-monoxide (CO), unburned hydrocarbons (UHC), NOx and soot emissions without the penalty of fuel consumption [1][2][3]. Interactions between the individual injections in a multiple injection process are the key to comprehend the soot generation mechanism which could reduce soot emission [1][3]. In the previous literatures, multiple injections have shown potent for simultaneous reduction of NOx and soot emission in the diesel engine [4][5][6][7].

In non-reacting conditions, the spray of the main injection penetrates faster within a shorter dwell time investigated by Mie-scatter and CFD models [8]. When the two-stage injection duration are same, the second injection vapor phase penetration is longer and faster [9][10][11][12]. For combustion characteristics, ignition delay of main injection is much shorter than that of the pilot injection and it may be shorter or longer with the dwell time increasing due to the different entrainment of surrounding gas [8]. In the multiple injection strategy investigation, the dwell time between injections and the pilot injection duration were seen as the two main factors. Seong-Young Lee et al. [13] found that it exists a slight reduction of the soot mass at the $0.3 / 0.65 / 1.2 \mathrm{~ms}$ condition. Fang et al. [14]measured the soot production of the biomass to liquid fuel using multiband flame measurement and two-color pyrometry. They found that the pilot injection results in a lower soot level compared with single injection with the same injection quality, while the pilot injection shown little impact on No. 2 diesel soot generation. However, in the study of [15], more fuel quantity during the first injection resulted in less soot emission with no increase in NOx emission when the pilot injection quantity is relative small to the main injection. Coupling the two factors, Carlucci et al. [16] found that both injection timing and duration show similar effect on the soot formation and oxidation. From the discussion before, in conslusion the soot formation in the multiple injection strategy isn't still precisely understanding.

In this study, the ignition delay, reacting spray liquid length and total soot mass evolution of 0\# fossil diesel were measured in a high-temperature high-pressure constant volume combustion chamber, the objective is to explore the effects on soot formation of $0 \#$ diesel under different dwell time and pilot injection duration in the constant volume chamber. In the next research, the dwell time will be extended. Schlieren and $\mathrm{OH}$ chemiluminescence imaging are going to be used for further analysis.

The rest of this article is structured as follows: the material and methods section present the test rig, test matrix and optical setup. Results are composed of three sections: ignition delay, the reacting spray liquid length, the spatial soot concentration distribution and total soot mass evolution under dwell time and pilot injection duration. 


\section{Material and methods \\ Test Rig}

The experiments were carried out in a high-temperature high-pressure constant volume combustion chamber. The cross section of the chamber is depicted in Fig. 1. Optical access is provided by four quartz windows at each side, $100 \mathrm{~mm}$ in diameter and $70 \mathrm{~mm}$ thick. The volume of the chamber is 12 liters, including the volume of the heating cartridges which are installed at the bottom inside the chamber. A single-hole injector with $0.18 \mathrm{~mm}$ diameter nozzle was mounted at the top of the chamber. The gas inside the chamber is injected by the high-pressure air holders and controlled by the inlet and outlet valves mounted at the bottom of the chamber. More details on the experimental equipment can be found in Ref. [17].

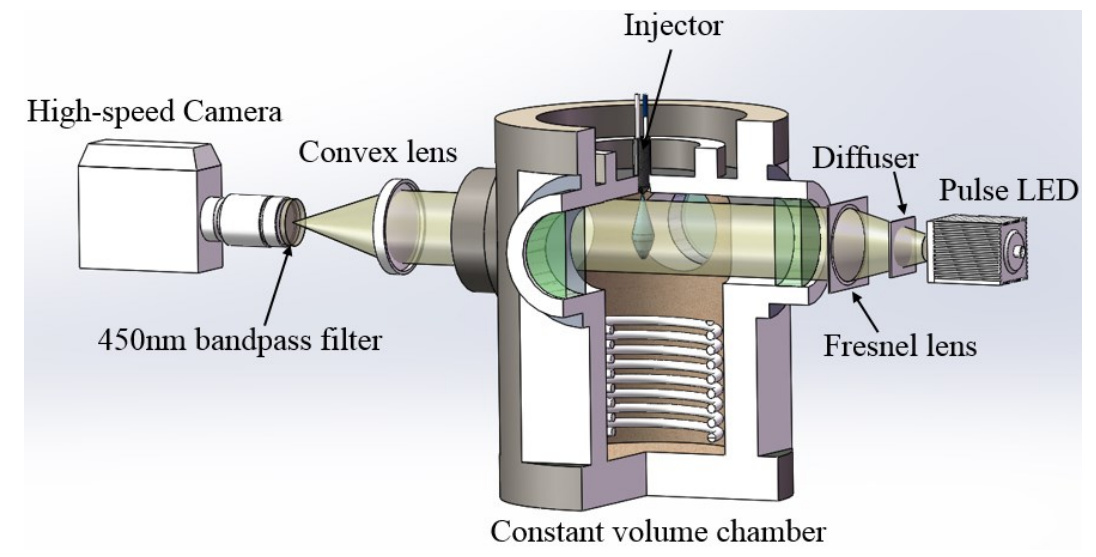

Fig. 1. Schematic of experimental setup

\section{Test matrix}

The operating condition of ignition delay and soot mass tests was maintained with ambient temperature $900 \mathrm{~K}$, ambient pressure 45 bar and injection pressure $150 \mathrm{MPa}$. The gas inside the chamber was pure air. Point 1 was employed for ignition delay and all the points was used for the soot evolution and reacting spray liquid length tests. In the study, all the set time were energizing timing. A wide range of dwell time (DT=400 $\mu \mathrm{s}, 600 \mu \mathrm{s}, 800 \mu \mathrm{s})$ was tested at a fixed pilot injection and the actual dwell time defined as the interval time of the beginning timing of the two-stage injection is $667 \mu \mathrm{s}, 1066 \mu \mathrm{s}$ and $1366 \mu \mathrm{s}$, respectively. The pilot injection energizing time (PIE) sweeps from $532 \mu \mathrm{s}$ to $709 \mu \mathrm{s}$ and the main injection(MI) is constant at $1773 \mu$ s energizing time. The single injection was seen as the reference. During the measurement, each condition was set as 10 times, and the interval $10 \mathrm{~s}$ to decline the uncertainty of the slight fluctuation of ambient temperature and pressure between two injections. The detailed test matrix is given in Table 1.

Table 1. Test matrix

\begin{tabular}{c|ccc}
\hline \hline Points & PIE $[\mu \mathrm{s}]$ & MI $[\mu \mathrm{s}]$ & DT $[\mu \mathrm{s}]$ \\
\hline \hline 1 & 532 & 1773 & $400,600,800$ \\
2 & 621 & 1773 & 800 \\
3 & 709 & 1773 & 800 \\
4 & 0 & 1773 & 0
\end{tabular}

\section{Optical setup}

Several optical diagnostics were employed in the measurements. Small aperture direct high-speed imaging was used for ignition delay and high-speed diffused back-illumination extinction imaging (DBIEI) was employed for soot mass evolution and liquid length in oxydic conditions.

\section{Diffused background illumination extinction imaging}

Fig. 1 shows the schematic of optical setup for DBIEI measurement. The setup implemented in this work consists of a pulse LED illumination system and a high-speed camera on opposing side of the spray in a line-of-sight arrangement. The pulse LED $(140 \mathrm{~W})$ triggered by the high-speed camera provides the successively stroboscopic light. The Fresnel lens $(\mathrm{d}=100 \mathrm{~mm}, \mathrm{f}=72 \mathrm{~mm})$ mounted close to the access window was used to magnify the illumination intensity and background light area. The engineer diffuser $\left(a=203 \mathrm{~mm}, \alpha=20^{\circ}\right)$ directs a bundle of 
diffused rays that will reduce beam steering caused by gas density gradients with minimal light intensity loss in hightemperature conditions.

The transmitted light of the LED and flame luminosity was collected by high-speed CMOS camera running at 60 $\mathrm{kHz}$ (Photron SA-Z). The camera lens used was a 105-mm f/2.8 Nikkor lens. The filter used was a $450 \mathrm{~nm}$ bandpass filter (FWHM $10 \mathrm{~nm}$ ). The convex lens $(\mathrm{d}=150 \mathrm{~mm}, \mathrm{f}=400 \mathrm{~mm})$ was employed dwindle the images size that focused on the lens of the camera. The measurement mechanism of DBIEI technology is based on Beer-Lambert Law [18]:

$$
\frac{I-I_{\text {flame }}}{I_{0}}=\exp (-K L)
$$

In Eq. $1, I$ is the sum of the transmitted LED intensity and the flame natural luminosity, $I_{\text {flame }}$ is the flame intensity corrected between every two successive LED pulses, $I_{0}$ is the incident intensity acquired at the time of injection, $K$ is the dimensional extinction coefficient and $L$ is the path length through the soot cloud. Soot volume fraction is based on small particle Mie theory [18][19]:

$$
f_{v}=\frac{\lambda}{k_{e}} \cdot k
$$

Where $f_{v}$ is soot volume fraction, $\lambda$ is the wavelength of the captured light $450 \mathrm{~nm}, k_{e}$ is the dimensionless optical extinction coefficient. $k_{e}$ can be obtained from the Rayleigh-Debye-Gans (RDG) theory as $k_{e}=7.61$. The details of the RDG theory and all the parameters used for calculating the $k_{e}$ are referenced from [19][21]. As a consequence, the sum of soot mass $\left(\mathrm{m}_{\text {soot }}\right)$ along the line-of-sight at each pixel was derived from Eq. 3 using an assumed density of $1.8 \mathrm{~g} / \mathrm{cm}^{3}$ for soot $(\rho)[22]$.

$$
m_{\text {soot }}=\rho K L \frac{\lambda}{\kappa_{e}} \times \text { pixel area }
$$

\section{Ignition delay and liquid-phase penetration}

For the ignition delay measurement, the transient combustion process images were captured by the same high speed camera with DBIEl at 60000 frames per second with a resolution of $896 \times 368$ pixels and an exposure time of $0.248 \mu \mathrm{s}$.

As mentioned before, the DBIEI is based on the light extinction by the soot particles. Obviously, the liquid phase can reduce the light intensity and the sign can be shown in the window. Moreover, the spray penetrates from the left to the right in the access. The liquid length (LL) was also quantified from DBIEI images following the approach recommended from Engine Combustion Network (ECN) [23]. The only difference is that the temporal liquid length evolution here was obtained from images averaged from 10 repetitions at each time position rather than just a one time-averaged value. The details for this process can be found in [24].

\section{Results and discussion \\ Flame luminosity and ignition delay}

Fig. 2 shows the time-sequence flame luminosity images after the start of the main injection (AMI) for the Point 1. For all the dwell time, main combustion started while the pilot combustion was still active. It means that the dwell time should be extended for further investigation. As the DT became longer, main combustion started when the pilot combustion was extinguished, as shown in the cases DT=600 $\mu \mathrm{s}, 800 \mu \mathrm{s}$. Under all dwell time, the flame of the main injection tends to be stable after $1 \mathrm{~ms} \mathrm{AMI}$.

Fig. 3 shows the ignition delay of pilot injection, main injection and the lag time between them. It can be found that the ignition delay of all DT cases was shorter than the single injection, when ignition delay was observed to be approximately $0.73 \mathrm{~ms}$. One thing should be pointed that the ignition delay was elapsed time from the start of the main injection. Short dwell time in two-stage injection would reduce the premixed combustion phase and the slightly increased surrounding gas temperature enhance main injection combustion process. For the case DT=400 $\mu \mathrm{s}$, the fresh air was consumed by the pilot injection and the main injection phase was ignited in a high-concentration exhaust lately due to the fresh air consumption in the pilot combustion. With the dwell time increasing, the ID of the main injection is shorter because of the increased space for a better combustion mixture, which can be seen at 0.5 ms AMI in DT $=800 \mu$ s case. 

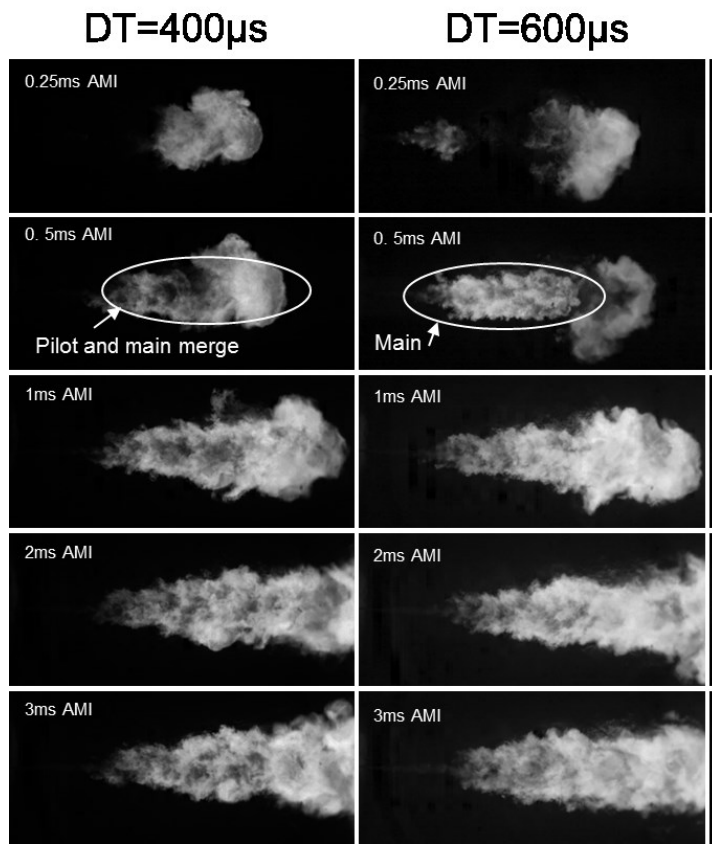

\section{DT $=800 \mu s$}
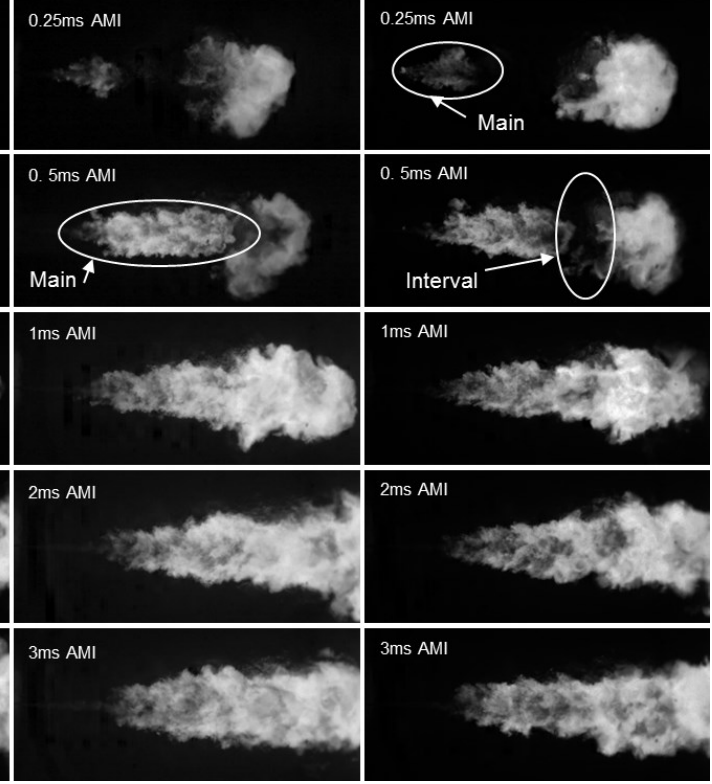

Fig. 2. Pilot and main flame luminosity after main injection (AMI) for DT $=400 \mu$ s (left column), DT=600 $\mu$ s (middle column), and $\mathrm{DT}=800 \mu \mathrm{s}$ (right column)

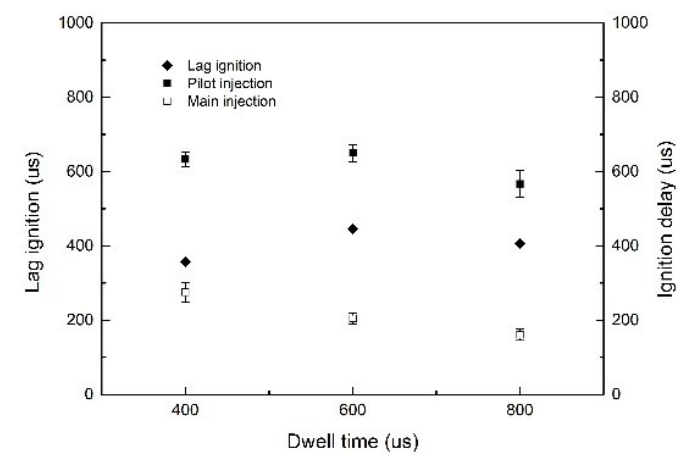

Fig. 3. Ignition delay with different dwell time (DT=400 $\mu \mathrm{s}, 600 \mu \mathrm{s}, 800 \mu \mathrm{s})$

\section{Liquid length}

Previous research shows that the LL has a great influence on the spray combustion and emission characteristics. Proper LL contributes to a good fuel/air mixing, while long liquid phase impinges on the piston bowl wall leading to a larger soot emission and reduced engine efficiency [25]. In-house image processing using Matlab from experimental shadowgraph images provided measurements of vapor penetration shown in Fig. 4.

Shown in the Fig. 4, it can be found that the reacting LL has been stabilized in all cases after $500 \mu$ s AMI. From Fig. 4 (a), it can be seen that the LL of DT=400 $\mu$ s is slightly higher than that of the other cases during the time from 500

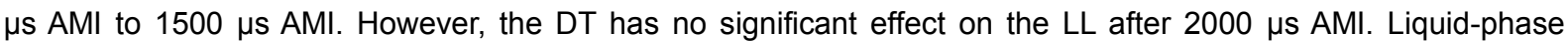
penetration is more associated with the ambient gas density and fuel density and viscosity. This trend is different with the spray-vapor penetration under two-stage injection. Coupled with Fig. 3, the spray in MI needs more time to ignite the spray due to low fresh air concentration. In Fig. 4 (b), it is shown that the LL overlap in the main evolution in all pilot injection cases. The results were found to be identical with the research in [8]. 


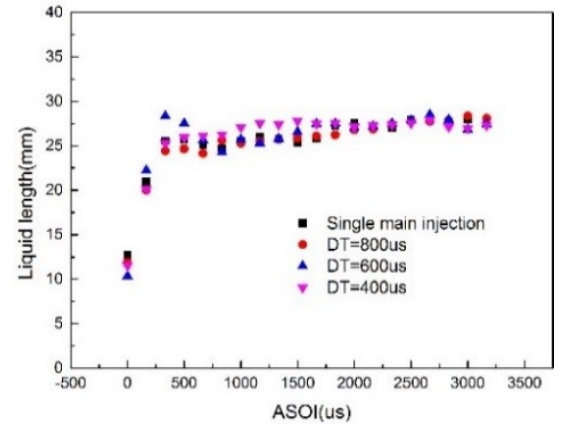

(a) Vapor penetvolumen length for DT

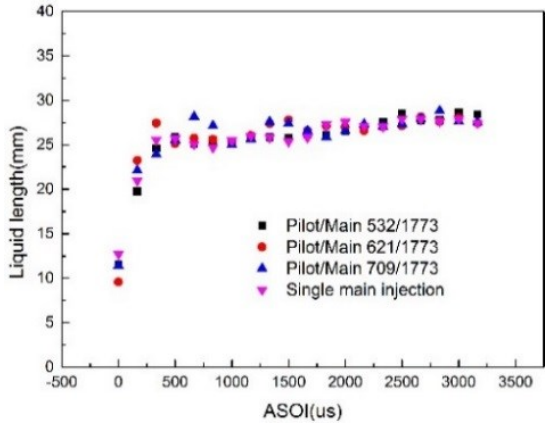

(b) Vapor penetration length for pilot

Fig. 4. Vapor penetration length for $D T=400 \mu \mathrm{s}, 600 \mu \mathrm{s}, 800 \mu \mathrm{s}$, (a) and PIE $=532 \mu \mathrm{s}, 621 \mu \mathrm{s}, 709 \mu \mathrm{s}$, (b)

\section{Soot analysis}

Taking into consideration Fig. 3, the stabilized time for comparison which was chosen for the study is kept constant at $2.5 \mathrm{~ms}$ AMI. Fig. 5 shows the typical combustion process of all PIE energizing timings and the single injection (without pilot injection) as the reference. The time chosen is $0.2 \mathrm{~ms}, 0.5 \mathrm{~ms}, 1 \mathrm{~ms}$ and $2.5 \mathrm{~ms}$ AMl. The yellow vertical line marks the illumination limitation. As mentioned before, the extinction in the left part inside the picture is the spray liquid.

Shown in Fig. 5, soot intensity can be found near the tip of the spray at $0.25 \mathrm{~ms} \mathrm{AMl}$ in the case DT=800 $\mu$ s. However, the spray is not obvious in the case DT=400 $\mu \mathrm{s}$. It may be caused by the dissatisfaction with the injector needle electromechanical delay due to the such short dwell time. It can also be found that the highest soot concentration located in the middle section of the flame at $0.5 \mathrm{~ms}$ AMl that is consistent with the results in [8]. Generally, the high temperature and high $\mathrm{C} / \mathrm{O}$ location exists near the flame in the diffused flame combustion. In addition, the highest soot concentration appears in the tip of the flame. However, the soot in the flame tip is much lower than that in the middle of the flame. Similar to the results of ignition delay in dwell time, the longer dwell time accelerates the soot formation in main injection due to the wide space between two flames for entrainment. Lack of the interactive effect of multiple injection, it needs more time for the reference case to reach the soot formation environment. In addition, the soot concentration of main injection is lowest in the case DT=400 $\mu$ s. At the time of $2.5 \mathrm{~ms} \mathrm{AMl}$, it can also be found that the soot formation increases with the longer dwell time. Especially, the soot concentration of the main injection in DT=400 $\mu$ s is slightly lower than that in single injection. shown in the soot distribution evolution, the soot formation is obviously affected by the surrounding emission caused by the pilot injection. The main injection spray was ignited in the burning environment caused by the pilot injection combustion. Fig. 6 gives the total soot mass of all DT cases. The first soot peak level also appears in all cases which is also observed in [26]. It can be seen that the soot peak level and the total soot mass are higher than others when the dwell time became longer.

Fig. 7 shows the soot distribution of all PIE cases, the 2-D soot concentration distribution was shown in the Fig. 7(a) and the total soot mass evolution was shown in the Fig. 7(b). From the Fig. 7(a), it can be seen that the soot formation of the main under PIE cases is slightly higher than that of the reference. However, the pilot injection duration has no significant effect on the soot formation. Fig. 7(b) shows the soot mass evolution of pilot injection duration. It exists overlap among three pilot injection duration in the time between $2.5 \mathrm{~ms}$ to $3.5 \mathrm{~ms}$ after the first energizing timing. In the whole evolution, the main injection soot mass has no difference except the lower in the case $\mathrm{PIE}=621 \mu \mathrm{s}$. 


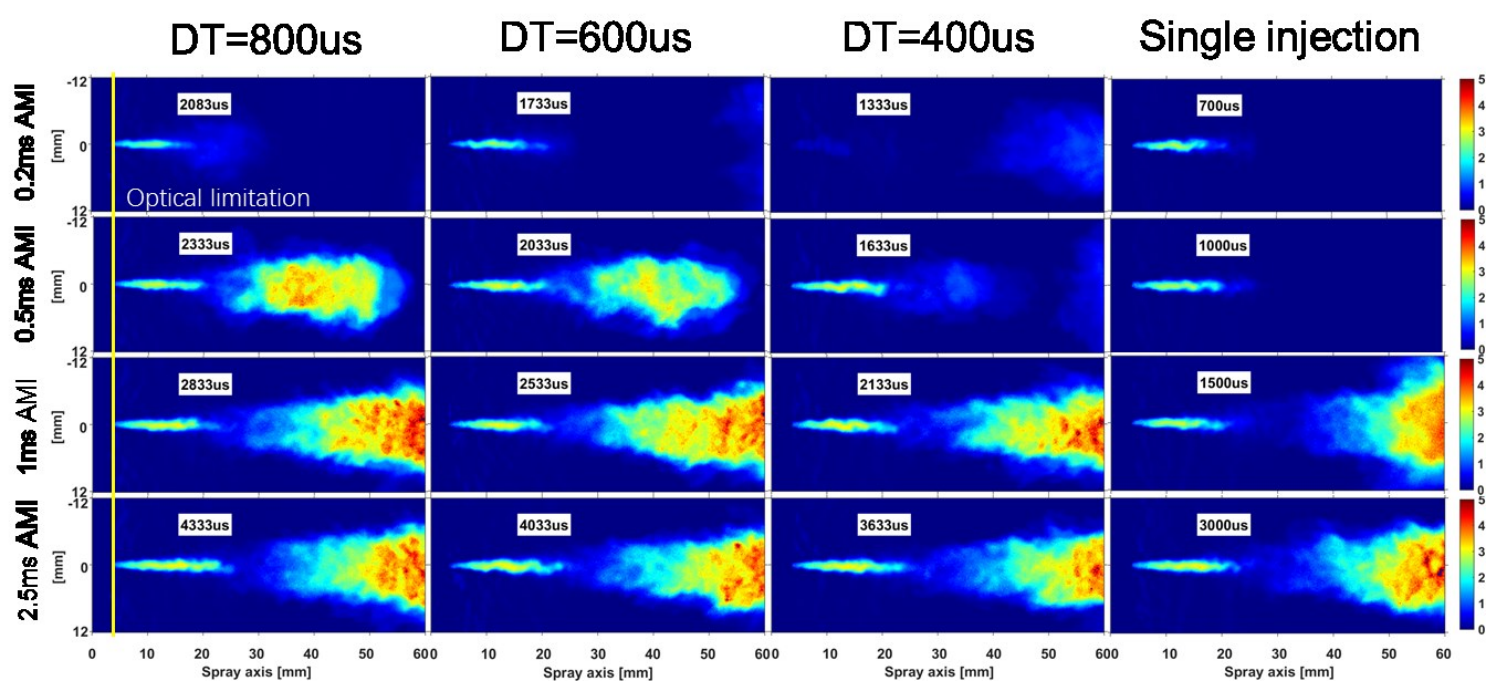

Fig. 5. Soot evolution of DT cases

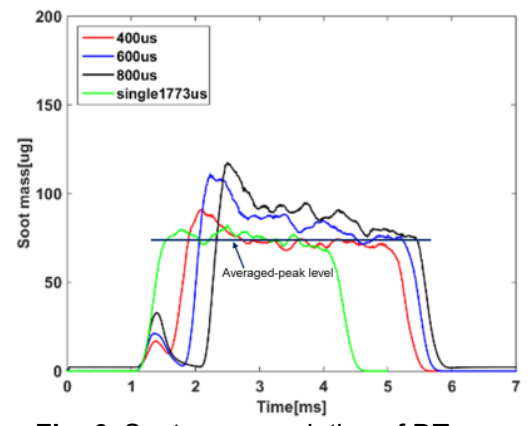

Fig. 6. Soot mass evolution of DT cases

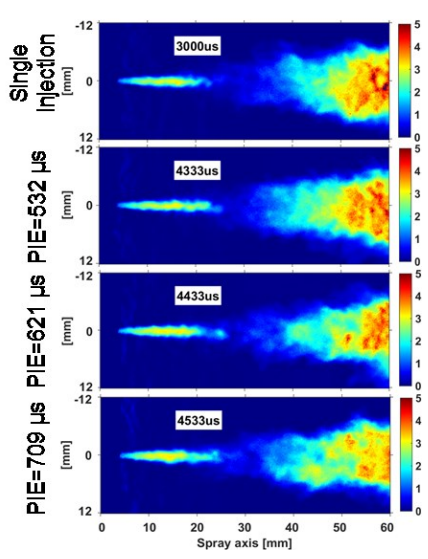

(a) 2-D soot concentration

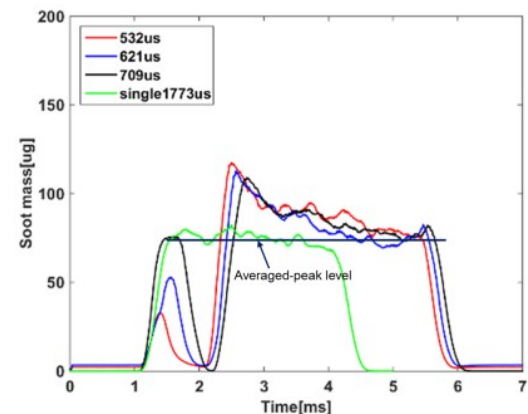

(b) Total soot mass evolution

Fig. 7. Soot distribution of PIE cases

\section{Conclusions}

In the paper, BDIEI technique was employed to detect liquid length and total soot mass, ignition delay was investigated by direct high-speed camera. The test matrix contains different DT (400 $\mu \mathrm{s}, 600 \mu \mathrm{s}, 800 \mu \mathrm{s})$ and PIE $(532 \mu \mathrm{s}, 621 \mu \mathrm{s}, 709 \mu \mathrm{s})$. The constant ambient condition inside the chamber is ambient temperature $900 \mathrm{~K}$, injection pressure $150 \mathrm{MPa}$ and ambient gas pressure $45 \mathrm{bar}$. All the points were measured in a constant volume combustion chamber equipped with a single-hole injector. The fuel used is $0 \#$ diesel. Conclusions are summarized as follows:

- In a such short dwell time, ignition delay decreases with the increasing dwell time, and the flame boundary of two injection is blurry in the case $D T=400 \mu \mathrm{s}$. DT $=400 \mu \mathrm{s}$ is dissatisfied with the injector needle delay

- For the liquid length, shorter dwell time leads to slightly longer liquid-phase penetration. However, pilot/main ratio shows slight impact, all the curves are overlapped. 
- It can be seen that the max soot concentration is located in the center of the soot distribution. The soot formation of the reference is lower than that of the DT cases, except the DT=400 $\mu$ s is similar. In the total soot mass evolution, the first peak level is found in all cases except the reference. The comparison shows that the total soot mass increases with the increase of dwell time while the pilot injection duration shows no effect. In all the comparison, the soot production of the main injection in the two-stage injections are higher than that of the reference.

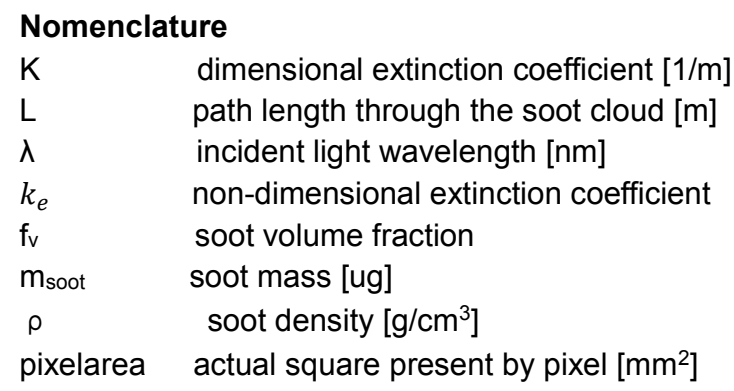

\section{Acknowledgements}

This research was supported by the National Natural Science Foundation of China (No. 51176066). Practice Innovation Project of Jiangsu Province (SJLX15 0491) and Natural Science Foundation of Jiangsu Province (BK20161349).

\section{References}

[1] Y. Imaoka, K. Shouji, T. Inoue, T. Noda. A study of a multistage injection mechanism for improving the combustion of direct-injection gasoline engines, SAE Int. J. Engines 8 (2015) 1080-1087.

[2] D. Martin, J. Stratmann, P. Pischke, R. Kneer, M.-C. Lai, Experimental investigation of the interaction of multiplegdi injections using laser diagnostics, SAE Int. J. Engines 3 (2010) 372-388

[3] J. O'Connor, M. Musculus. In-cylinder mechanisms of soot reduction by close-coupled post-injections as revealed by imaging of soot luminosity and planar laser-induced soot incandescence in a heavy-duty diesel engine, SAE Int. J. Engines 7 (2014) 673-693.

[4] Chen SK. Simultaneous reduction of NOx and particulate emissions by using multiple injections in a small diesel engine. SAE paper. 2000:01-3084

[5] Mohammad Reza Herfatmanesh, Pin Lu, Hua Zhao et al. Experimental investigation into the effects of twostage injection on fuel injection quantity, combustion and emissions in a high-speed optical common rail diesel engine[J]. Fuel, 109 (2013) 137-147

[6] Kim H, Lee J, Kim K, Lee K. Effect of the Atkinson cycle combined with calibration factors on a two-stage injection-type premixed charge compression ignition engine[J]. Energy Fuel 23 (2009) 4908-4916

[7] Kim YJ, Kim KB, Lee KH. Effect of a 2-stage injection strategy on the combustion and flame characteristics in a PCCl engine. Int J Autom Technol, 2011;12:639-44

[8] Khanh Cung, Seong-Yong Lee, Abdul Moiz et al. Spray-combustion interaction mechanism of multipleinjection under diesel engine conditions[J]. Proceedings of the Combustion Institute, 35(2015) 3061-3068.

[9] L.M. Pickett, S. Kook, T.C. Williams. Transient liquid penetration of early-injection diesel sprays, SAE Int. J. Engines 2 (2009) 785-804.

[10] S. Skeen, J. Manin, L.M. Pickett, Visualization of Ignition Processes in high-pressure sprays with multiple injections of n-dodecane, SAE Int. J. Engines 8 (2015) 696-715.

[11] Scott Skeen, Julien Manin, Lyle M Pickett. Visualization of Ignition Processed in High-pressure Sprays with Multiple Injections of n-Dodecane[C]. SAE Paper, 2015-01-0799

[12] Ahmed Abdul Moiz, Khanh D. Cung, Seong-Young Lee. Simultaneous Schlieren-PLIF Studies for Ignition and Soot Luminosity Visualization with Close-Coupled High-Pressure Double Injections of n-Dodecane[J]. Journal of Energy Resources Technology, 2017/ 012207-1

[13] Ahmed Abdul Moiz, Muhsin M Ameen, Seong-Young Lee et al. Study of soot production for double injections of $\mathrm{n}$-dodecane in $\mathrm{Cl}$ engine-like conditions[J]. Combustion and Flame, 173(2016) 123-131.

[14] Wei Jing, Zengyang Wu, Tiegang Fang. Spray combustion of biomass-based renewable diesel fuel using multiple injection strategy in a constant volume combustion chamber[J]. Fuel, 181(2016) 718-728.

[15] Shayler et al. SAE Paper, 2005-01-0375

[16] Carlucci P, Ficarella A, Laforgia D. Effects of pilot injection parameters on combustion for common rail diesel engines. SAE 2003-01-0700; 2003

[17] Da li, Zhixia He, Tiemin Xuan et al. Simultaneous capture of liquid length of spray and flame lift-off length for second-generation biodiesel/diesel blended fuel in a constant volume combustion chamber[J].Fuel,2017(189):260-269

[18] H. Zhao, N. Ladommatos. Optical diagnostics for soot and temperature measurement in diesel engine[J]. Prog. Energy combust.1998(24):221-255 
[19] Liang Zheng, Xiao Ma, Zhi Wang et al. An optical study on liquid-phase penetration, flame liftoff location and soot volume fraction distribution of gasoline-diesel blends in a constant volume vessel[J]. Fuel,139(2015),365373

[20] Julien Manin, Lyle M. Pickett, Scott A. Skeen et al. Two-color diffused back-illumination imaging as diagnostics for time-resolved soot measurements in reacting sprays[C]. SAE paper,2013

[21] Koylu U. O. and Faeth G. M. Optical properties of overfire soot in buoyant turbulent diffusion flames at long residence times. Journal of heat transfer, 116(1):152-159, 1994.

[22] Scott A. Skeen, Julien Manin, Kristine Dalen et al. Extinction-based imaging of soot processes over a range of diesel operating conditions[C]. 8th U. S. National Combustion Meeting,2013

[23] Engine Combustion Network webpage: http://www.sandia.gov/ecn (online)

[24] Manin, J., Bardi, M., and Pickett, L.M., "Evaluation of the liquid length via diffused back-illumination imaging in vaporizing diesel sprays," International Symposium COMODIA 2012 SP2-4, 2012

[25] Lequien Guillaume, Berrocal Edouard, Gallo Yann, et al. Effect of jet-jet interactions on the liquid fuel penetration in an optical heavy-duty DI diesel engine, SAE 2013-01-1615.

[26] Yuri Martin Wright, Pickett, L.M et al. Onset and progression of soot in high-pressure n-docecane sprays under diesel engine conditions[J]. International Journal of Engine Research. 